\title{
Hepatic Amebiasis
}

José Maria Salles, Luis Alberto Moraes and Mauro Costa Salles
Federal University of Pará, Belém/PA; Medical Science School Santa Casa, São Paulo/SP, Brazil

Amebiasis can be considered the most aggressive disease of the human intestine, responsible in its invasive form for clinical syndromes, ranging from the classic dysentery of acute colitis to extra-intestinal disease, with emphasis on hepatic amebiasis, unsuitably named amebic liver abscess. Found worldwide, with a high incidence in India, tropical regions of Africa, Mexico and other areas of Central America, it has been frequently reported in Amazonia. The trophozoite reaches the liver through the portal system, provoking enzymatic focal necrosis of hepatocytes and multiple micro-abscesses that coalesce to develop a single lesion whose central cavity contains a homogeneous thick liquid, with typically reddish brown and yellow color similar to "anchovy paste". Right upper quadrant pain, fever and hepatomegaly are the predominant symptoms of hepatic amebiasis. Jaundice is reported in cases with multiple lesions or a very large abscess, and it affects the prognosis adversely. Besides chest radiography, ultrasonography and computerized tomography have brought remarkable contributions to the diagnosis of hepatic abscesses. The conclusive diagnosis is made however by the finding of Entamoeba histolytica trophozoites in the pus and by the detection of serum antibodies to the amoeba. During the evolution of hepatic amebiasis, in spite of the availability of highly effective drugs, some important complications may occur with regularity and are a result of local perforation with extension into the pleural and pericardium cavities, causing pulmonary abscesses and purulent pericarditis, respectively The ruptures into the abdominal cavity may lead to subphrenic abscesses and peritonitis. The treatment of hepatic amebiasis is made by medical therapy, with metronidazole as the initial drug, followed by a luminal amebicide. In patients with large abscesses, showing signs of imminent rupture, and especially those who do not respond to medical treatment, a percutaneous drainage must be performed with either ultrasound or computerized tomography guidance. Surgical drainage by laparotomy is reserved to patients with secondary infections.

Key Words: Entamoeba histolytica, hepatic ameabiasis.

Amebiasis is the most aggressive protozoal disease that affects the human bowel, considered the second or third leading cause of death amongst the parasitic diseases, surpassed only by malaria and schistosomiasis.

In spite of the great number of asymptomatic patients infected by Entamoeba dispar or even by some strains

Received on 03 April 2002; revised 08 August 2002.

Address for correspondence: Dr. José Maria Salles. Av. Visconde de Souza Franco, 1348, Zip code: 66053-000, Belem-Pará, Brazil. Phone (55 91) 223-7659. Fax (55 91) 223-5487. E-mail: salles@nautilus.com.br.

The Brazilian Journal of Infectious Diseases 2003;7(2):96-110 (C) 2003 by The Brazilian Journal of Infectious Diseases and Contexto Publishing. All rights reserved. of Entamoeba histolytica that remain in the luminal surface of the bowel, amebiasis in its invasive form, is responsible for enteric syndromes, ranging from frank dysentery to fulminant colitis, which is highly lethal. Once through the bowel wall, trophozoites invade the portal circulation and disseminate systemically, reaching the liver to cause hepatic amebiasis.

Reported in the metropolitan regions of developing countries, hepatic amebiasis is endemic in Thailand, India, Egypt and South Africa, with high mortality rates [1]. In Mexico, a national serosurvey demonstrated that $8.4 \%$ of the population was exposed to invasive amebiasis, representing 1 million cases of the disease [2]. In Brazil, though there is lack of national reports, 
the incidence of hepatic amebiasis differs from one region to another, being uncommon in the south and prevalent in the north [3,4]. In this region hepatic amebiasis is very important and its high frequency has been reported by different investigators [5-8] (Table 1).

Until now, it remains unclear why hepatic amebiasis is more common in men than in women. Individuals in the fourth and fifth decades of life are most commonly afflicted.

\section{Pathogenesis}

Despite the new concepts regarding amebiasis, with special emphasis on the biological differences between Entamoeba dispar (noninvasive, nonpathogenic, nonantigenic), responsible for more than $90 \%$ of amebic infections and Entamoeba histolytica (invasive and pathogenic), some aspects of the pathogenesis of amebiasis are still unclear [9].

The trophozoite may remain confined to the intestinal lumen as a simple boarder, feeding on bacteria and cellular debris. Sometimes, however, depending on the genetic and immunoenzymatic profile, and the parasite's ability to produce proteolytic enzymes and to resist to complement-mediated lysis, the trophozoite becomes virulent, and starts its invasion of the intestinal mucosa. It can then establish persistent extra-intestinal infection throughout the portal veins radicles, most commonly in the liver [10]. In regions where amebiasis is endemic, a variety of conditions, including climate conditions, overcrowding, ignorance, poverty, malnutrition, suboptimal sanitation, impaired cellular and humoral immunity, play an important role in this exacerbation [11].

Following depression of the protective mucus blanket, trophozoites attach to the cells of interglandular epithelium and, with the aid of proteolytic enzymes that degrade elastin, collagen and fibronectin, especially cysteine proteinase, phospholipase and hemolysin [12], they invade the colonic epithelium by disruption of the extra cellular matrix. The first signal of colonic aggression may be manifested as a non-specific thickening of the mucosa or by pinhead-size micronodules, visible by sigmoidoscopy. Peptide- mediated lysosome enzymes released by the lysed polymorphonuclear leucocytes and monocytes, contribute to the destruction of host tissue and extend the lesion. The trophozoites invade the submucosa and spread out laterally, creating the classic flask-shaped amebic ulcer [13] (Figure 1).

Histopathology shows necrotic areas and vascular congestion. There is little inflammation in contrast with the extension of the lesion. The amoebas may be found in the surface layer of the ulcers or in adjacent sites [14]. Invading the small vessels of submucosa, the trophozoites gain access to the superior mesentery, and disseminating throughout the blood stream, they reach the portal system to cause microembolus and infarction of small vascular branches. Resisting complementmediated lysis, the trophozoites pass to the liver, causing areas of focal necrosis.

Amebic lysis of neutrophils at the edge of the lesion, releases mediators, and this leads to hepatocyte death, extending the damage to distant hepatic cells and increasing the number of small lesions that coalesce to develop a larger hepatic lesion, which is unsuitably named the amebic abscess. The content of its central cavity is a thick, clotty exudate. This is generally homogeneous, and varies in color, ranging from creamywhite to dirty brown and pink, similar to "anchovy sauce" [15] (Figure 2). This material is almost always sterile, except when a secondary infection has occurred, allowing differential diagnosis from a pyogenic abscess. The amebae can be found at the edge of the lesion, but are rarely detected in the pus or within the abscess cavity itself [16].

The hepatic lesion is usually solitary, and most frequently is located in the right lobe, situated contiguously with the liver capsule. Variable in size, in some cases it may occupy more than $80 \%$ of the whole liver surface (Figure 3). This may be explained by the larger volume of the right lobe, which receives most of the venous drainage from the right colon, a segment of the bowel frequently affected by intestinal amebiasis [17]. The amebic lesions of the left lobe are less common, and multiple abscesses may occur in advanced cases of amebiasis. Table 2 shows the topography of hepatic lesions reported in Pará state. 
Table 1. Hepatic amebiasis in Pará. Reports from 1958 to 1999

\begin{tabular}{lc}
\hline Authors & No. Cases \\
\hline Maneschy & 40 \\
Salles & 12 \\
Guimarães & 75 \\
Ribeiro Neto & 35 \\
Chaves L.C. & 90 \\
Pardal & 16 \\
Moraes, HUJBB & 104 \\
\hline
\end{tabular}

Table 2. Hepatic amebiasis in Pará. Localization of lesions

\begin{tabular}{lccc}
\hline Authors & \multicolumn{3}{c}{ Localization } \\
\cline { 2 - 4 } & Right lobe & Left lobe & Multiple \\
\hline Maneschy & 40 & 0 & 0 \\
Guimarães & 72 & 3 & 0 \\
Ribeiro Neto & 29 & 2 & 0 \\
$\quad$ Pardal & 40 & 0 & 0 \\
Salles & 12 & 1 & 0 \\
Chaves L.C. & 82 & 7 & 1 \\
Moraes & 99 & 3 & 2 \\
\hline
\end{tabular}

Figure 1. Invasion of submucosa by trophozoites. The lesion spreads out laterally, creating the flask-shaped amebic ulcer. (Histopathology, UFPA, Araújo R.).

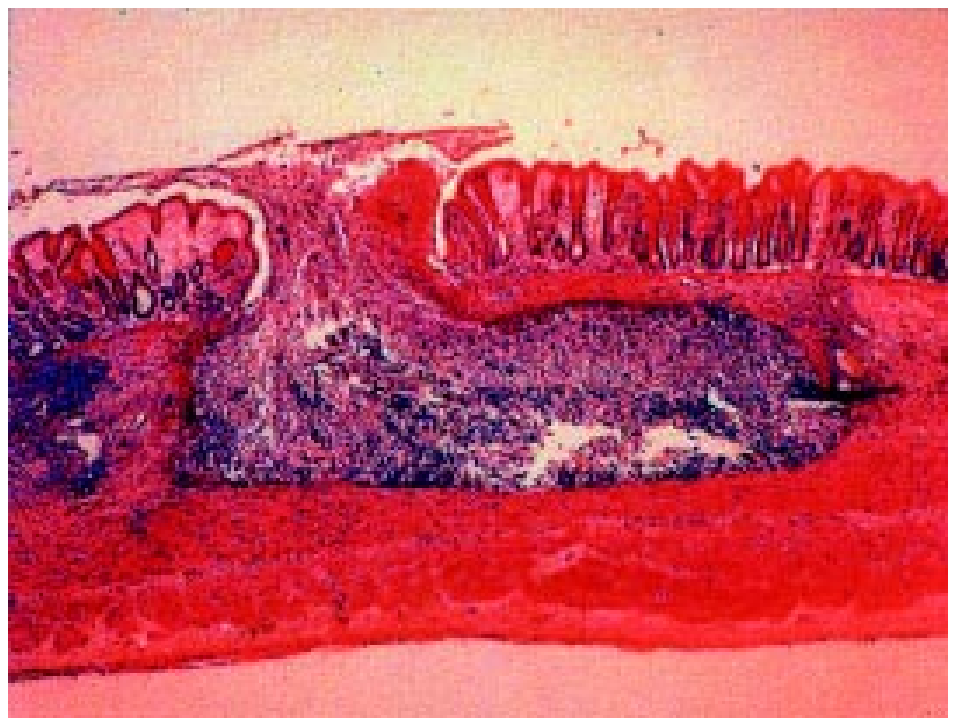


Figure 2. Right lobe amebic lesion ruptured, showing a necrotic cavity with a thick dirty brown exudate, compared to "anchovy sauce". (Dep. Cirurgia HUJBB).

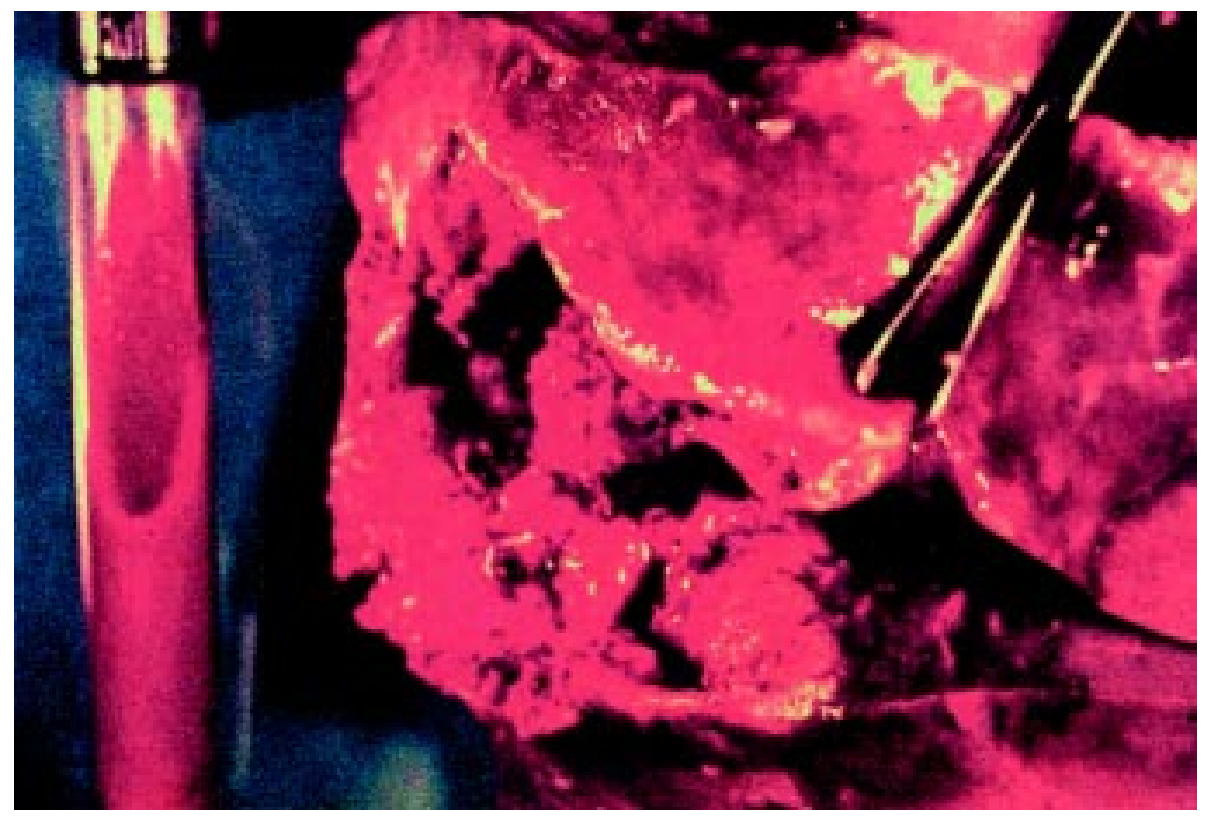

Figure 3. Large amebic liver abscess, attaining almost the whole right lobe. (Araújo, R. Anatomia Patológica, UFPA).

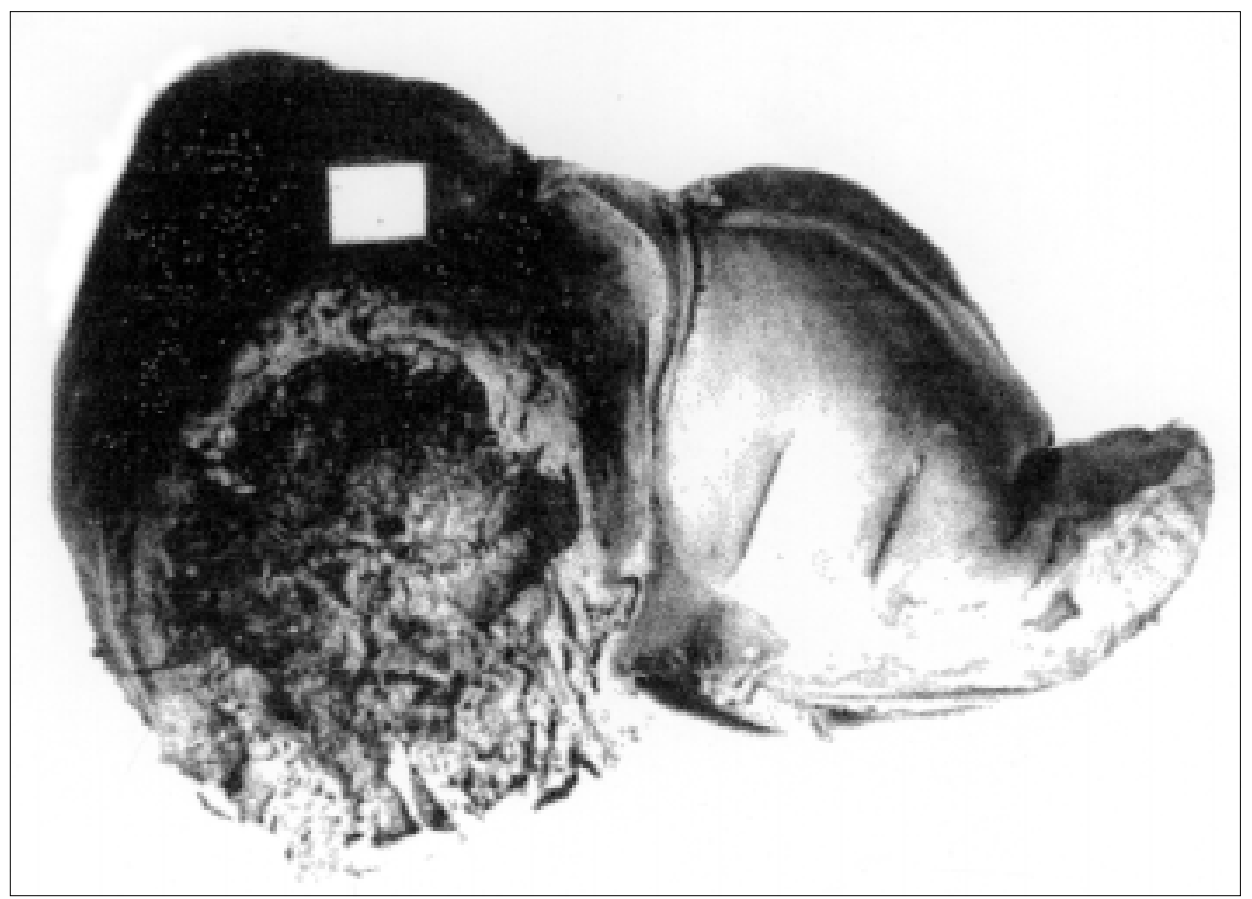




\section{Clinical Manifestations}

The clinical manifestations of hepatic amebiasis are so typical that they might suggest the diagnosis in the areas where it is prevalent, such as in Amazonia. Some days or months after the onset of classic dysentery, or as usually happens, without any symptoms or a history of intestinal amebiasis, the clinical features begin to appear. Despite the size and the site of the hepatic lesion, the most common symptoms are fever, pain and hepatomegaly.

In patients with acute onset, the fever is generally present in more than $90 \%$ of the cases. It is often very high, continuous or intermittent and accompanied by chills, weakness and profuse perspiration. In chronic forms the fever is low and develops more gradually, without chills or sweating.

Abdominal pain is the earliest and most frequent complaint, present in almost $100 \%$ of the patients. It starts as a feeling of heaviness, and then becomes a sharp pain that increases according to the position of the body, compelling the patient to find relief in bed by turning to the opposite side of the lesion. In abscesses of the right lobe the pain is felt in the right hypochondria, in the right subcostal area or in the cystic point, and may radiate to the shoulder, right side of the neck or the back. In abscesses of the left lobe, the pain is located in the epigastria and left hypochondria and radiates to the left back and left scapular regions.

Besides these prevailing symptoms, patients may also complain of malaise, nausea, vomiting, anorexia and weight loss. Diarrhea may be present in about $2 \%$ of the cases, with 4 to 5 episodes per day of a watery stool, with mucus and blood, tenesmus, abdominal cramping and distension due to potassium loss. In some patients, when diarrhea is absent sigmoidoscopy may show the amebic ulcers [19].

Jaundice is an unusual feature, reported in only 5\% of the cases. Its appearance suggests the existence of large or multiple abscesses, bacterial infection and derangement of hepatic function [20]. The presence of jaundice may worsen considerably the prognosis. Dry cough, chest pain and decreased breath may be due to pleuropulmonary extension of the inflammatory process in the lesions of the superior surface.
Hepatomegaly is the most important physical sign in hepatic amebiasis. The enlargement of the liver varies with the size and the site of the lesion. There may be a generalized enlargement, downward enlargement or upward enlargement of the right or left lobe, compressing the diaphragm. In this situation there is a decrease in the ability to breathe, and the patient complains of dyspnea. In the larger abscesses, a mass or a lump may sometimes be seen in the right hypochondria or epigastria [15] (Figure 4). In the abscesses of the left lobe, the mass is palpable at the left hypochondria. The tenderness may be diffuse or localized. In cases with severe tenderness, the patient avoids the palpation, even before the examiner reaches the affected area.

The symptoms of 104 cases of hepatic amebiasis admitted at Hospital João de Barros Barreto from 1990 to 2000 are given in Table 3 .

\section{Diagnosis}

After the old days of splenoportography and less sensitive tests, the non-invasive imaging procedures, including ultrasonography, computerized tomography, magnetic resonanceimaging and, principally serology, have dramatically improved the clinician's ability to promptly diagnosis hepatic amebiasis and quickly start treatment.

Among the laboratory findings, the blood count reveals a mild degree of anemia that may be either normochromic or hypochromic. In the majority of cases, a mild to moderate leukocytosis is present, with an average white blood cell count of 16,000 . In patients with multiple abscesses, or bacterial infection, the leukocytosis may be severe, accompanied by neutrophilia, with an increased percentage of immature forms similar to a leukemoid reaction [21].

The recovering of trophozoites and cysts of Entamoeba histolytica in feces of patients with hepatic amebiasis strengthens the hypothesis of amebic etiology. Liver function tests are not very helpful, presumably because too little liver tissue is affected. A moderate elevation of alkaline phosphatase, as well as hypoalbuminemia and transaminases, would suggest the possibility of a large abscess [22]. 
Table 3. Clinical symptoms of 104 cases of hepatic amebiasis in patients at the Hospital João de Barros Barreto

\begin{tabular}{lrr}
\hline Symptoms & \multicolumn{2}{c}{ Cases } \\
\cline { 2 - 3 } & No. & \% \\
\hline Fever & 102.0 & 98.0 \\
Pain & 104.0 & 100.0 \\
Hepatomegaly & 84.0 & 80.0 \\
Jaundice & 54.0 & 54.9 \\
Vomiting & 45.0 & 43.2 \\
Diarrhea & 37.0 & 35.5 \\
Weight loss & 32.0 & 30.7 \\
\hline
\end{tabular}

Figure 4. Lump visible at the epigastrium corresponding to a lesion of the left lobe.

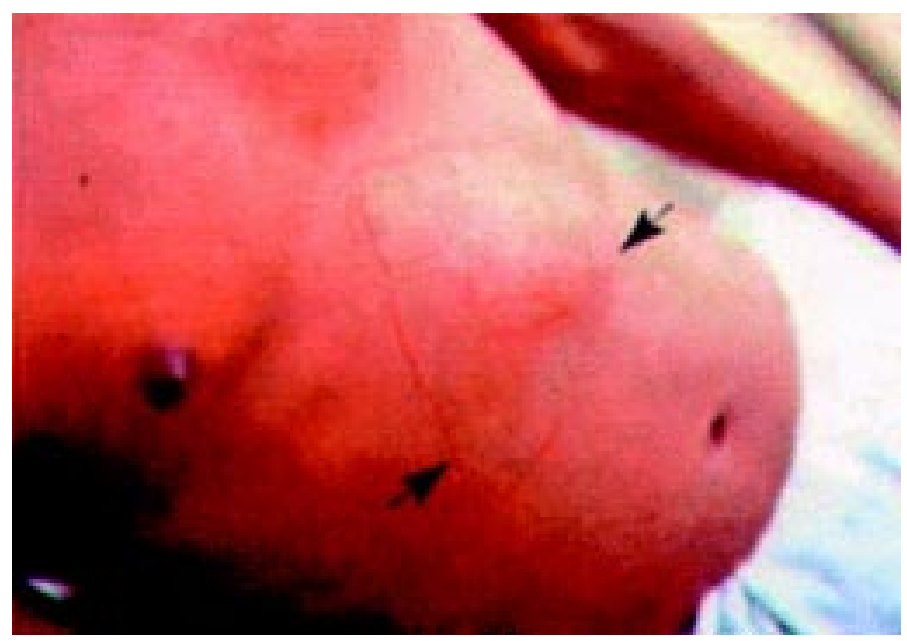

Figure 5. Elevation of the right hemidiaphragm due to an abscess of the right lobe.

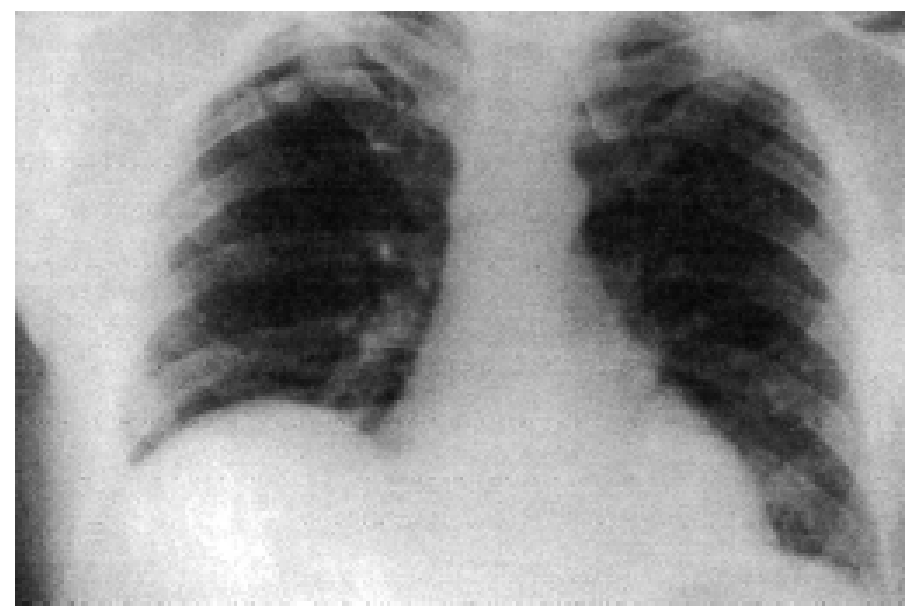


In imaging studies, an elevation of the right hemidiaphragm in chest radiography is a common find when there are lesions of the right lobe (Figure 5). In lesions of the left lobe, the elevation is seen on the opposite side [23]. Ultrasonography is the most widely used initial imaging procedure indicated for patients with a history and symptoms of hepatic amebiasis. In addition to its low cost and accessibility, it has the ability to rapidly detect hepatic lesions at the different stages of the disease, determining their number, size and exact position (Figure 6). It may even differentiate a solid tumor from an abscess and a biliary tract disease from a lesion. It is also very helpful in guiding percutaneous catheter liver drainage and in following the course of infection and its clinical resolution [24,25]. At ultrasonography the amebic hepatic lesion tends to be round or oval, hypoechoid, with well-defined margins (Figure 6).

The abdominal CT scan is another valuable imaging procedure, with greater resolution and sensitivity in detecting hepatic lesions, especially the smaller ones, which is useful for early diagnosis [27]. In the CT scan, an amebic abscess usually appears as a rounded, welldefined, low-density lesion, with an homogeneous septated cavity, and with considerable fluid (Figure 7).

In spite of the important support provided by imaging studies, the definitive confirmation of hepatic amebiasis is based on a demonstration of Entamoeba histolytica trophozoites in the aspirated pus, or more frequently from the necrotic material obtained by needle biopsy of the edge or the bottom of the lesion. Nevertheless, the ameba will be found in only a small percentage of cases.

Considering the humoral immune response to Entamoeba histolytica, serology has become a valuable tool for diagnosis, detecting specific circulating antibodies against the invasive forms, and indicating the etiology with a reasonable margin of safety, and therefore differentiating hepatic amebiasis from a pyogenic abscess [27]. Among the variety of serological tests available nowadays, indirect hemagglutination (IHA), even when used in serological studies, is a very sensitive assay, being positive in 90 to $100 \%$ of patients with liver amebiasis. Indirect immunofluorescence is also very helpful, giving values higher than 1:800 in about $70 \%$ of the suspects. Enzyme-immunoassay (ELISA), either IgG class or total immunoglobulin, is the most sensitive assay and now replaces IHA. It has a sensitivity of $98 \%$, and it is extraordinarily useful in the early stages of hepatic amebiasis [28].

Because of the low positivity of microscopic diagnosis, antigen detection can be an essential adjunct method. Recent studies indicate improved sensitivity and specificity of fecal antigen assays for invasive strains, with the use of monoclonal antibodies that can distinguish between Entamoeba histolytica and Entamoeba dispar [29]. Unfortunately this test is not yet available commercially.

\section{Differential Diagnosis}

Despite a similarity with several diseases such as hepatoma, acute cholecystitis, parasitic cysts, subphrenic and pulmonary abscesses provoked by bacteria, the differential diagnosis of hepatic amebiasis must be established principally against pyogenic abscess [30,31].

Although epidemiological information may show the patient to be from an area endemic for amebiasis, acute onset of fever, abdominal pain and hepatomegaly are common to both amebic and pyogenic abscesses, and laboratory findings and the images obtained from radiography, ultrasonography and CT scan studies, are not decisive for determining an absolute difference between amebic and pyogenic abscesses.

The real difference is based on the following:

Abscesses

Amebic Pyogenic

Serology (IHA/ELISA) positive negative

Bacteriology of the pus negative positive (*)

Demonstration of $E$. histolytica positive negative

Therapeutic efficacy metronidazole antibiotics $(* *)$

(*) Gram-negatives (E. coli, Klebsiella, Proteus, B. flagilis); (**) Aminoglycosides, cephalosporins, quinolones, clindamycin.

\section{Complications}

In spite of the availability of effective drugs, complications may be found with regularity during the course of hepatic amebiasis. Its appearance depends on the size, number and localization of the lesions, and they may interfere unfavorably with the prognosis of the disease. 
Firstly, the liver is prone to bacterial invasion due to its anatomical location and function. Since most of the blood supply from the large gut drains into the right lobe of the liver through the portal system, translocated organisms, such aerobic and anaerobic Enterobacteriaceae, may reach the hepatic sinusoids, being phagocytized most of the time. When the mononuclear-macrophage system is unable to destroy the invaders, they subsequently inflict cellular injury and secondary bacterial infection, producing clinical symptoms of severe illness that are distinct from those of amebic abscess [15]. There is the risk of sepsis, needing prompt diagnosis and therapy with antibiotics. Repeated liver aspirations without appropriate technique and asepsis may also be responsible. Under these circumstances Staphylococcus aureus is the principal invader [20]. Secondary infection is not a frequent complication, being reported only in $10 \%$ to $20 \%$ of the patients with large and multiple lesions.

The spreading of the amebic lesion to adjoining structures, involving a contiguous mechanism, is a frequently reported complication. The close vicinity of the diaphragm to the superior surface of the hepatic lesion may lead to inflammatory reactions of the diaphragm itself, subphrenic space, pleura, lungs and pericardium [32]. Clinically this can result in atelectasis, pleuritis, empyema and pulmonary condensation. These are frequently detected at the right hemithorax, corresponding to lesions of the right lobe of the liver, reported in most cases (Figure 8). An intensive pain localized over the lower rib cage on the right side, a dry cough, shortness of breath, and severe dyspnea in a patient with hepatic amebiasis, are suggestive symptoms of an initial pulmonary complication, that demands urgent chest radiographic or CT scan studies [33].

Due to the extreme fragility of the lesion wall and because of inner pressure, a rupture may occur at some point of the liver capsule, with extension into the pericardium, pleural and peritoneal cavities [34]. This is, in fact, one of the commonest complications of hepatic amebiasis, with an incidence varying from $5 \%$ to $20 \%$ of the cases. It often involves the right chest, although the left side can also be affected.
On the superior surface, when the abscess extends upward, the process reaches the diaphragm and the overlying pleura, causing empyema that can empty into a bronchus and form a broncho-pleurohepatic fistula. The invasion of the lung parenchyma by Entamoeba histolytica, leads to development of interstitial pneumonitis, followed by liquefaction and formation of a lung abscess. This abscess may rupture into a bronchus and provoke vomica, a sudden and profuse expectoration of putrid purulent matter [35,36]. Amebic pulmonary abscesses are prone to result from lesions of the right lobe, and their incidence varies from 2\% to 4\% (Figure 9). Among 104 cases of hepatic amebiasis studied in HUJBB, it was found in less than $2 \%$. In lesions of the left lobe, the same clinical syndromes can be seen at the left hemithorax [37].

The extension of the hepatic amebiasis to the pericardium, also through a mechanism of contiguity, is responsible for serious syndromes that range from mild pericarditis to catastrophic purulent pericarditis $[38,39,40]$. Although extremely uncommon in the cases of acute onset, this complication leads to a life threatening emergency, causing cardiac tamponment, and it is invariably lethal [41] (Figure 10). Rarely, a chronic perforation is described, giving rise to constrictive pericarditis. A sharp pain in the left hemithorax and clinical signs of pericarditis demand an immediate complementary investigation.

Sometimes, as a consequence of a downward extension, the hepatic lesion may leak into the peritoneal cavity as a localized abscess of the left anterior or posterior subphrenic spaces, or in the form of a free perforation, causing generalized peritonitis with consequent polymicrobial infection, and a syndrome of acute abdominal pain (Figure 11). This is the second most common complication of hepatic amebiasis after pleuropulmonary involvement, with an incidence varying from $5 \%$ to $10 \%$, and high mortality $[42,43,44]$. Ultrasonography and CT scan studies can identify the large hepatic abscesses ready to rupture, requiring immediate drainage.

A retrospective analysis of 104 cases with hepatic amebiasis studied at the HUJBB is given in Table 4. 
Table 4. Hepatic amebiasis. Complications reported in 104 cases

\begin{tabular}{lrr}
\hline Complications & No. & $(\mathbf{\%})$ \\
\hline Pleural effusion & 20 & $(19.2)$ \\
Empyema & 3 & $(2.8)$ \\
Pulmonary abscess & 2 & $(1.8)$ \\
Subphrenic abscess & 7 & $(6.7)$ \\
Peritonitis & 11 & $(10.5)$ \\
\hline
\end{tabular}

Figure 6. Ultrasonography showing a hepatic abscess of the right lobe.

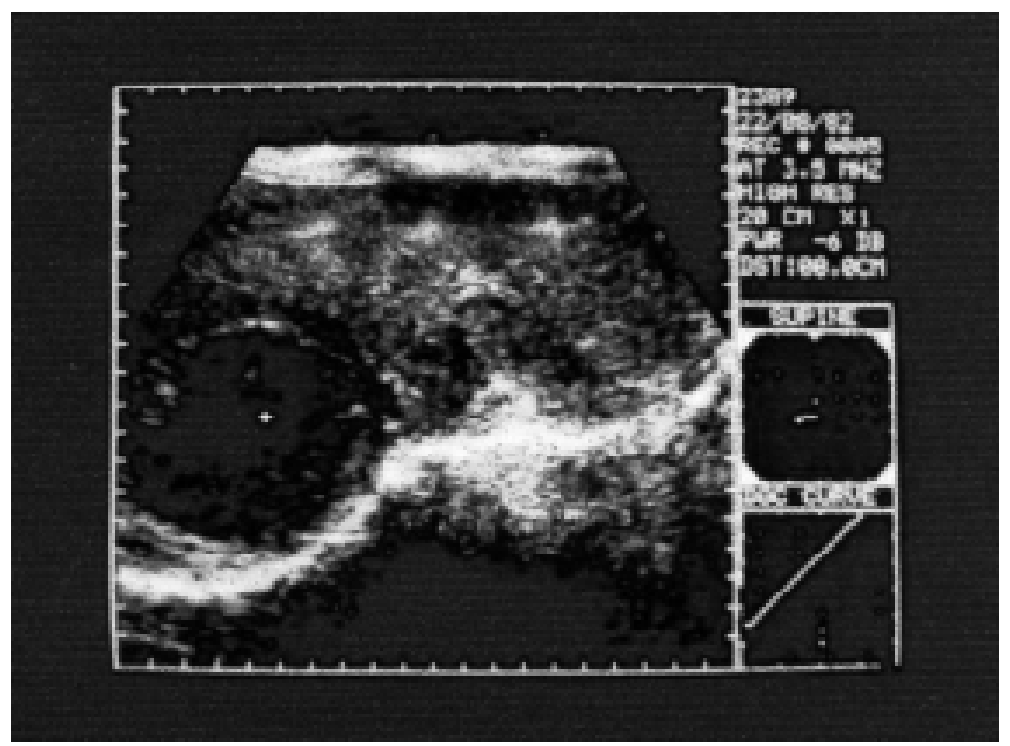

Figure 7. Abdominal CT scan showing a large amebic abscess of the right lobe (Dr. Cláudio Chaves, UEPA)

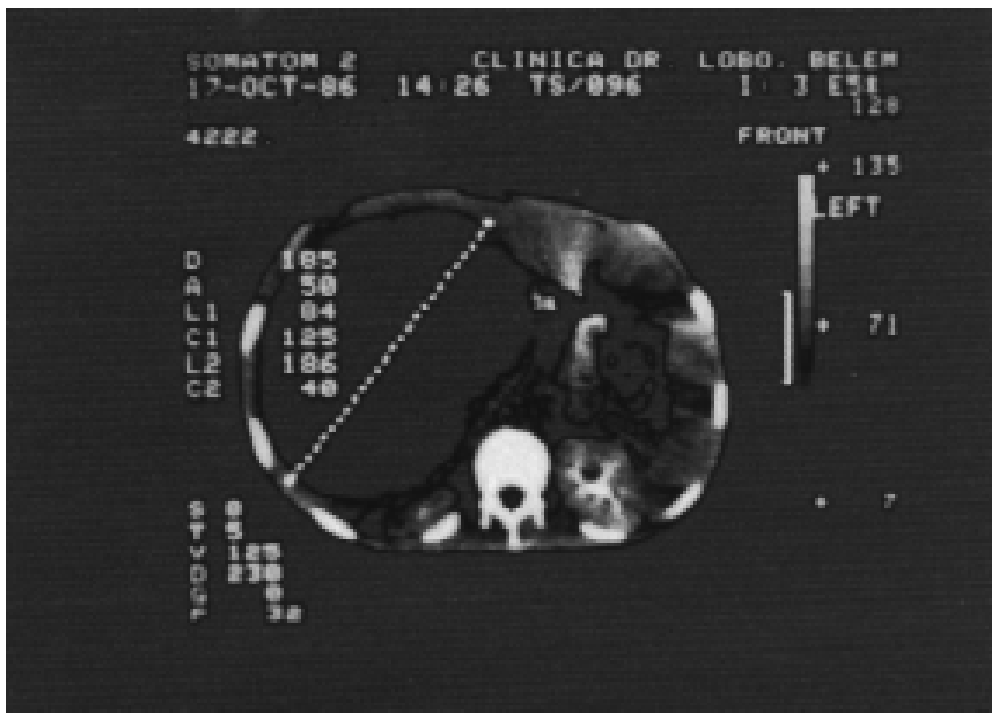


Figure 8. Pleuropulmonary complication due to the extension of a left lobe hepatic lesion.

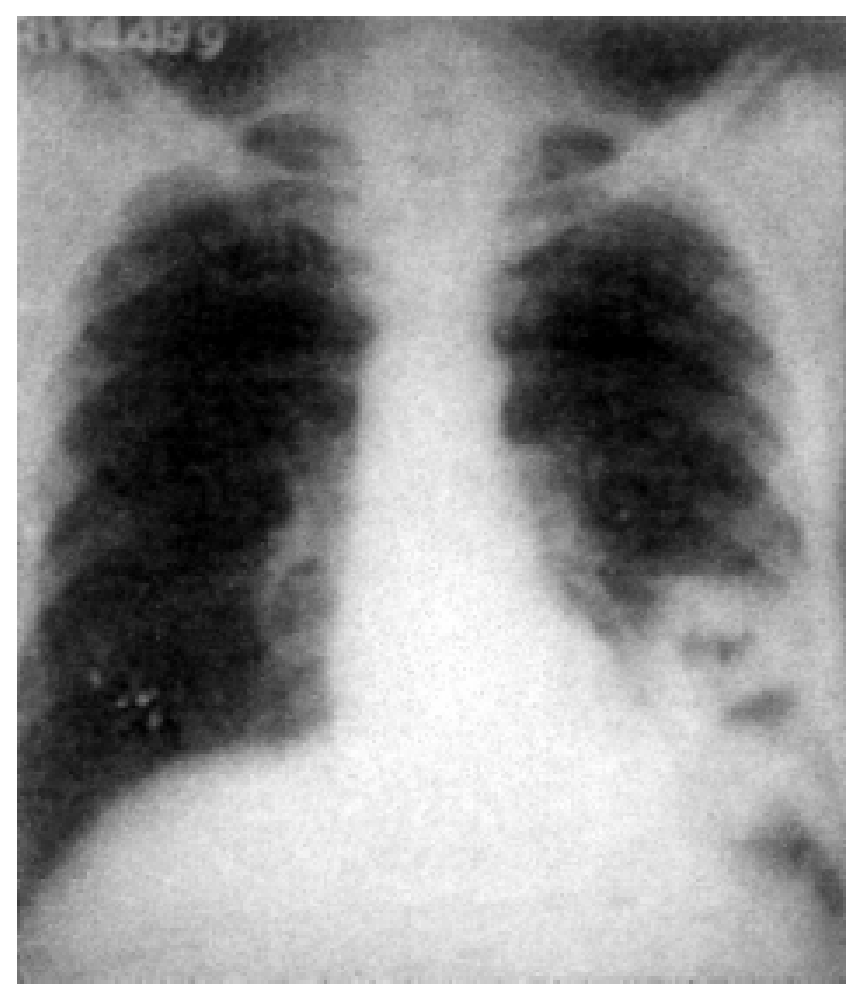

Figure 9. Pulmonary abscess due to a ruptured amebic liver lesion.

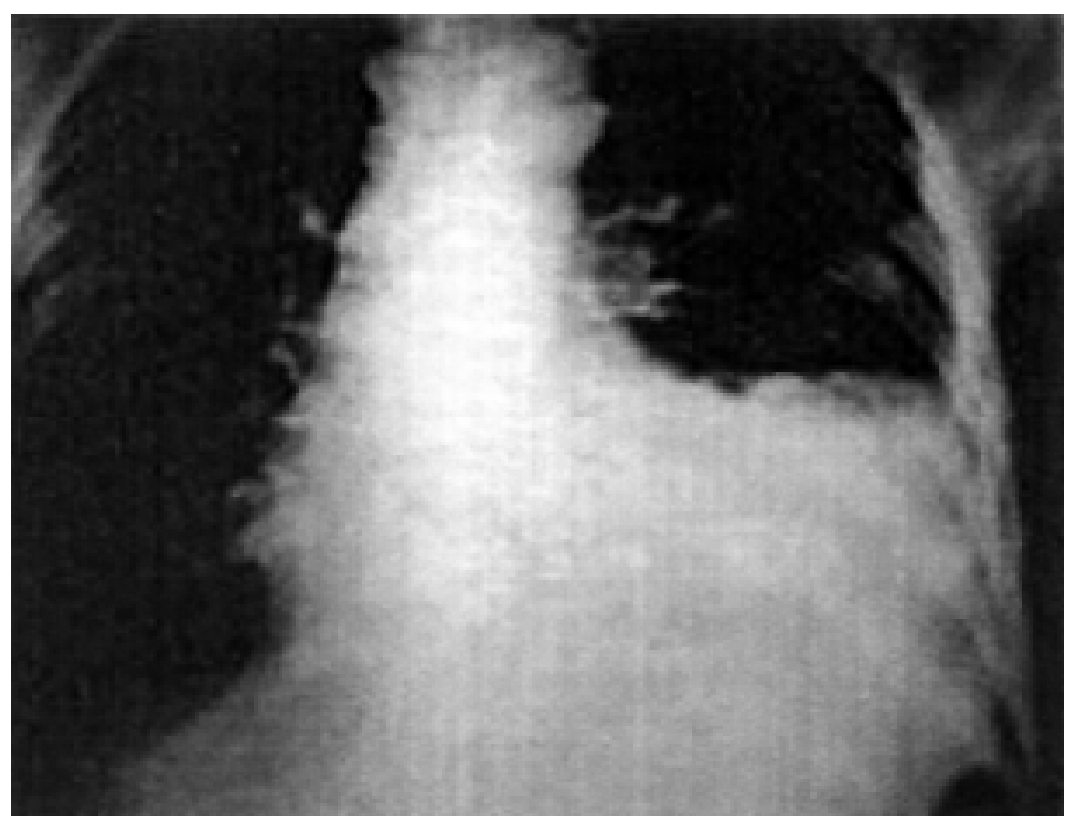


Figure 10. Constrictive pericarditis due to a rupture of a left lobe abscess. From Mandragon-Sancez, R.).

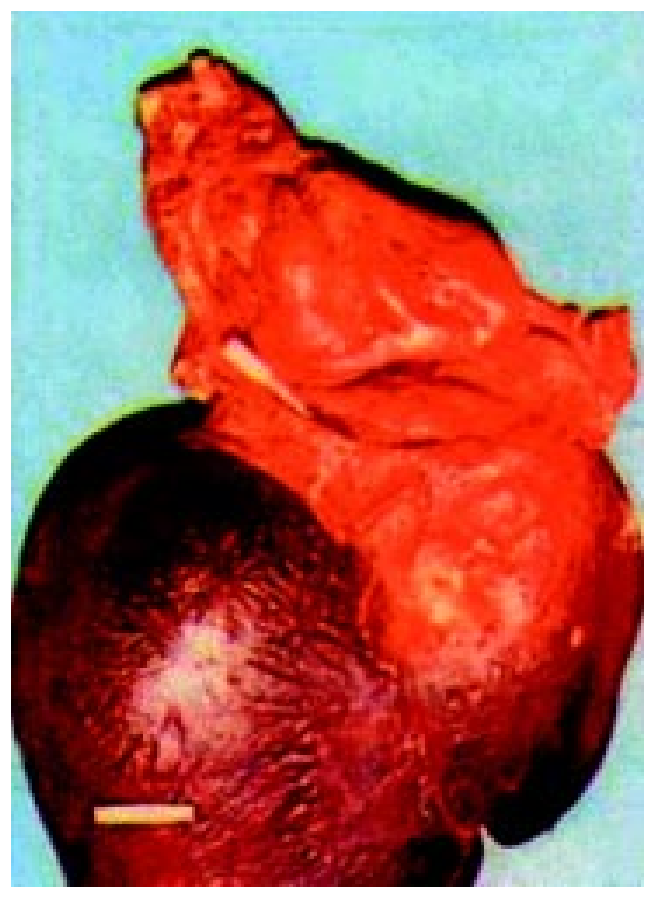

Figure 11. Retroperitoneum invasion due to an amebic liver lesion.

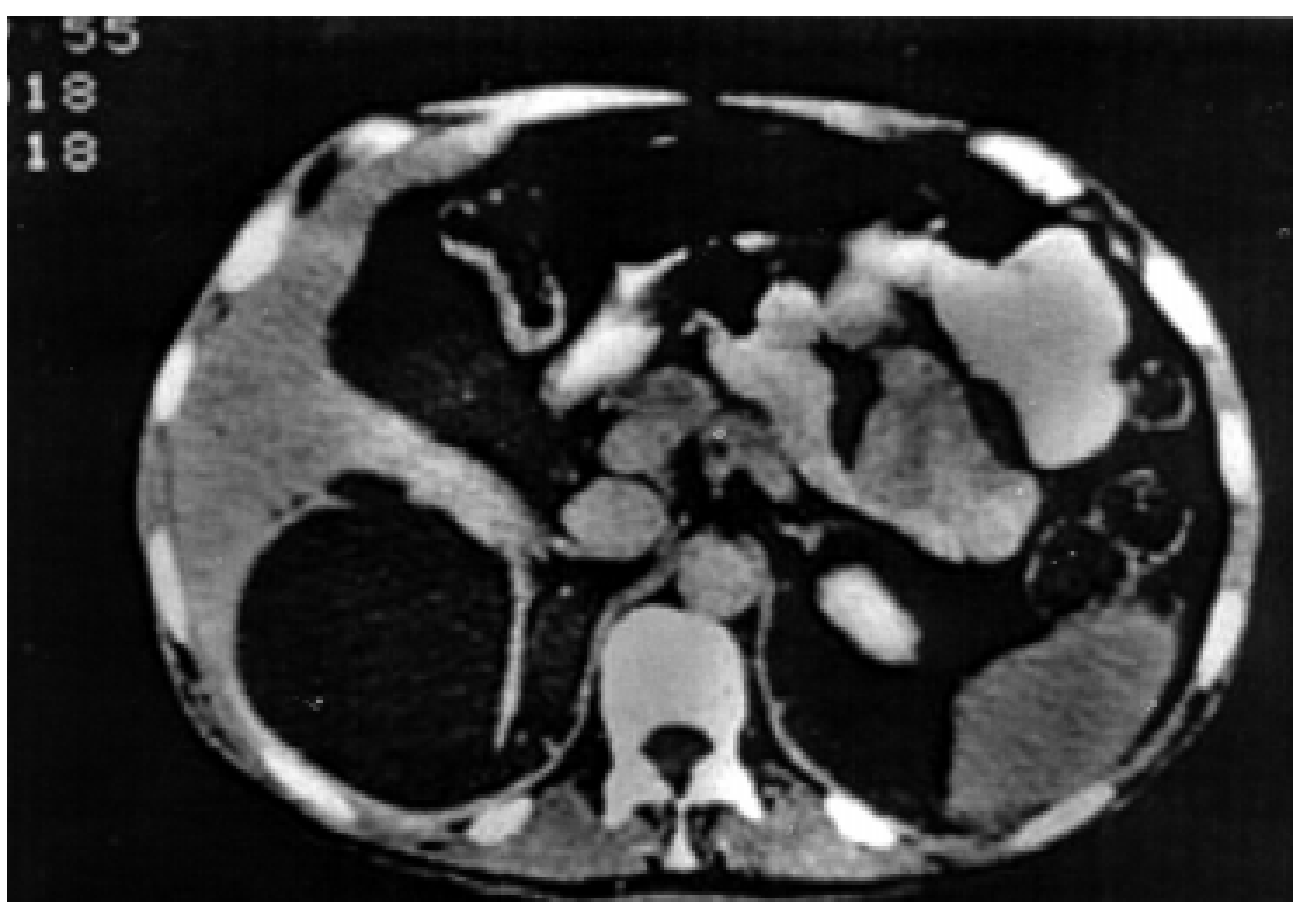




\section{Treatment}

The discovery of systemic amebicides, mainly in the nitroimidazole group, with high tissular diffusion, and enhanced capability to cross the wall and reach the interior of the abscess at a very high concentration (four times the MIC for Entamoeba histolytica), has been responsible for a dramatic change in the treatment of invasive amebiasis, reducing complications and therefore mortality.

In contrast with the last four decades, when patients with hepatic amebiasis were systematically submitted to surgical drainage by laparotomy, medical therapy nowadays is the treatment of choice, indicating surgical drainage only for extremely large lesions in which ruptures are believed to be imminent $[45,46]$.

Because of its highly lethal action against the trophozoite of Entamoeba histolytica and favorable pharmacokinetics, with fast intestinal absorption, excellent bioavailability, widespread distribution in most body tissues and a half-life of 14 hours, metronidazole is the indicated drug for the treatment of hepatic amebiasis [47].

In critically ill patients, with large and multiple abscesses, metronidazole is used at $500 \mathrm{mg}$ by IV infusion every 8 hours, for five or ten days. By oral route the metronidazole dose must be 750 to $800 \mathrm{mg}$, three times daily for 10 days for adults and $50 \mathrm{mg} / \mathrm{kg} /$ day for children. Most patients treated with metronidazole improve after 3 or 4 days and cure has been reported in more than $90 \%$ of the cases. This drug is available in capsules of 250 and $500 \mathrm{mg}$, and $500 \mathrm{mg}$ for IV infusions.

Common side effects of metronidazole include nausea, vomiting, headache, abdominal discomfort and a metallic taste mentioned by almost all patients. More serious adverse reactions, such as ataxia, confusion, insomnia, parenthesis or even seizures are rarely seen. Since this drug crosses the placenta and enters the breast milk, its indication must be considered carefully for pregnant cases. Though there is insufficient data on human beings, the mutagenic and carcinogenic potential of metronidazole has been widely studied in animals [48].
During the last few years two imidazole derivates have been introduced in Brazil, both with high amebicide action and an extended half-life, especially secnidazole [49]. Tinidazole is indicated as a metronidazole substitute for non-complicated cases of invasive amebiasis, and is used orally, at $2 \mathrm{~g}$ daily, for 5 days [50]. Secnidazole has the same pharmacodynamics as metronidazole, but it has different pharmacokinetics, with a much-extended half-life, maintaining high concentrations in tissues for more than 24 hours. Some studies with secnidazole have shown that a single daily dose of $2 \mathrm{~g}$ for five days is effective for uncomplicated amebic abscesses. Nevertheless, treatment of hepatic amebiasis with large and multiple lesions must be made with metronidazole [51].

Nitazoxanide, a new, recently introduced, drug, with efficacy against cysts and trophozoites of Entamoeba histolytica has shown good results in the treatment of intestinal amebiasis [52].

Chloroquine, an antimalarial drug is also effective against the trophozoite of Entamoeba histolytica. With an excellent tissue distribution, it maintains high concentrations in hepatic parenchyma and therefore within the amebic lesion. Its use is restricted; it is recommended exclusively as an adjunct of metronidazole, for patients with large and multiple amebic abscesses. The indicated posology is $300 \mathrm{mg}$ every 12 hours, followed by $300 \mathrm{mg}$ daily for 21 days. To prevent relapses after the treatment with metronidazole, even in the absence of dysentery and other symptoms of enteric amebiasis, a luminal amebicide must be administered to eradicate cysts and trophozoites from the intestine. It is important to remember that in accordance with the pharmacokinetics of imidazoles, these drugs have a short stay in the bowel lumen, which is not sufficient for an effective action against the amoebas [53].

In Brazil two luminal amebicides, teclosan and ethophamide, are available for use. Teclosan is an acetoamid derivative, without intestinal absorption, remaining in the bowel and excreted with the feces. Is available in capsules with 100 and $500 \mathrm{mg}$ and syrup with $50 \mathrm{mg} / 5 \mathrm{ml}$. The recommended posology is 500 $\mathrm{mg}$ orally every 12 hours for three days or $1,500 \mathrm{mg}$ 
Table 5. Hepatic amebiasis treatment of 104 cases

\begin{tabular}{lc}
\hline Treatment & No. $(\boldsymbol{\%})$ \\
\hline Clinical therapy & $56(53.8)$ \\
Clinical therapy and drainage & $30(28.7)$ \\
Laparotomy & $18(17.5)$ \\
Death & $05(4.8)$ \\
\hline
\end{tabular}

taken as a single dose [54]. Ethophamide is a clephamide derivative, without intestinal absorption and is excreted only by the digestive route. With good activity against cysts and trophozoites in the bowel lumen it is used $500 \mathrm{mg}$ twice a day for three days [55].

Many investigators have recommended the treatment of patients with HIV infection following the evidence that Entamoeba histolytica is able to produce a lecithin mitogen for lymphocytes that could trigger HIV-1 replication [56]. The finding of patients with hepatic amebic lesions who are HIV seropositive, some of them with an infection developed after the onset of amebic liver abscess, seems to be proof of this relationship [57]. Nevertheless invasive amebiasis is uncommon in a considerable number of HIV positive patients, and the parasite that is sometimes identified is Entamoeba dispar [58,59].

During the treatment of hepatic amebiasis, in addition to chemotherapy, a percutaneous liver aspiration may be required, guided by ultrasonography and performed with care and asepsis to avoid contamination $[60,61]$. Aspiration generally enhances clinical recovery, accelerates resolution and prevents complications. This procedure is perfectly indicated in the following circumstances [62]:

Persistence of clinical symptoms, especially abdominal pain and fever.

Large liver abscesses of the right lobe in imminence of rupture.

Abscesses of the left lobe.

Pregnant patients with amebic lesion for whom metronidazole is contraindicated.

Amebic liver abscesses with pleuropulmonary complications.

Lack of clinical improvement.
The early diagnosis of hepatic amebiasis by serology and imaging studies, the availability of effective drugs and percutaneous drainage has made surgical treatment very rare [63]. Nevertheless, considering the very high mortality of the syndromes of rupture, with serious pulmonary implications, pericarditis, or more frequently, subphrenic abscess or even peritonitis with sepsis, surgical treatment can be absolutely necessary, and should be supplemented by antibiotics and other therapy $[64,65]$.

In the absence of complications, rapid clinical improvement is seen. Patients gradually respond to metronidazole therapy alone within a few days to a week, with disappearance of fever, right upperquadrant pain, anorexia and other usual complaints. Hepatic cavity healing may occur within from 3 to 12 months and must be monitored by ultrasonography.

Nowadays, the prognosis of hepatic amebiasis, diagnosed early and properly treated, is quite favorable and mortality should be approximately zero. Higher rates of mortality are directly linked to serious complications, mainly pericarditis and peritonitis.

The treatment of 104 cases of hepatic amebiasis in HUJBB is summarized in table 5. Table 5. Hepatic amebiasis. Treatment of 104 cases

\section{Prevention}

Amebiasis, being a social problem, its definitive eradication, depends on the improvement of public health measures, adequate sanitation, clean water supplies and above all, better health education. This has not been an easy task in areas in which resources for health care programs are scarce.

Undoubtedly the development of a vaccine would be the most economical strategy for the prevention of amebic infection and consequently invasive amebiasis. Although not yet commercially available, there has been continuous progress in this field.

\section{References}

1. Walsh J.A. Prevalence of Entamoeba histolytica infection. In: Ravdin JI, ed. Amebiasis: human infection by Entamoeba histolytica. New York: Livingstone, 1988:93-105. 
2. Cabalero J., Viveros M., Salvatierra B., et al. Seroepidemiology of amebiasis in México. Am J Trop Med Hyg 1998;50:412-9.

3. Rey L. Entamoeba histolytica e Amebíase II: A doença. In: Parasitologia Médic. 2 ed. Rio de Janeiro; Guanabara Koogan, 1991.

4. Maneschy L.A.P. Abscesso Amebiano na Amazônia. Thesis (Livre Docência) Centro Biomédico da Universidade Federal do Pará. Belém, 1974.

5. Ribeiro Neto H.J., Beckman C.R. Abscesso Amebiano do Fígado. In: Hepatologia Clinica e Cirúrgica. São Paulo; Servier, 1986:541-8.

6. Chaves L.C. Abscesso Amebiano do Fígado, Dissertação (Mestrado em Cirurgia Gastrenterológica), Universidade Federal do Rio de Janeiro. Rio de Janeiro, 1987.

7. Pardal P.P.O., et al. Estudo epidemiológico, clínico e laboratorial do abscesso hepático amebiano no Pará. Ver Soc Brás Méd Trop 1991;24:138-43.

8. Moraes L.A. Estudo clínico de 104 casos de abscesso hepático amebiano do fígado no HJBB. In: Rev Brás Cir 1999;227:54-60.

9. Reed S.L. New concepts regarding the pathogenesis of amebiasis. Clin Infect Dis 1995;21(suppl):S182-5.

10. Ravdin J. I. Amebiasis. Clin Infect Dis 1995;20: 1453-8.

11. Cunha A.S., et al. Amebíase. In: CastroL., Rocha O., Cunha A. Tópicos em Gastrenterologia. 1.ed., Rio de Janeiro; Medisi 1991;54: 287-316.

12. Castellano-Espinosa M., Marinez-Paloma A. Pathogenesis of intestinal amoebiasis: from molecules to disease. Clin Microbiol Rev 2000;13: 318-30.

13. Ravdin J.I., Croft B.T., Guerrant R. Cytopathogenic mechanisms of Entamoeba histolytica. J Clin Invest 1981; 68: 1305-13.

14. Brandt H., Perez-Tamoyo R. Pathology of human amebiasis. J Pathol 1977; 1:351-68.

15. Adams E.B., MacLeod O. In: Invasive Amebiasis: Amebic liver abscess and its complications. Medicine 1977;56:325-34.

16. Rodrigues Filho A., Maneschy L.A., Vianna C.M., et al. Abscesso amebiano do fígado. Revista de Ciências Biológicas 1963; 1 :163-76.

17. Kapoor O.P. Amebic liver abscess. Bombay Hospital Journal 1990; 332: 5-8.

18. Sharma M.P., Acharya S.K., Verna N.B., et al. Clinical profile of multiple amoebic abscesses, J Assoc Physicians India 1990;38:837-9.

19. Donovan J.A., Yellin A.E., Rals P.W. Hepatic abscess. World J Surg 1991; 15: 162-9.

20. Ahmed A., MacAdams P.W.J., Sturm A.W. Systemic manifestations of invasive amebiasis. Clin Infect Dis 1992; $15: 74-82$.

21. Petri W.A., Petri Jr., Upinder S. Diagnosis and management of amebiasis. Clin Infect Dis 1999;29:117-25.
22. Salako I.A. Liver function tests in the diagnosis of hepatic amebiasis. J Trop Med Hyg 1967;70:19-22.

23. Kimura K., Stoopen M., Reeder M.M., et al. Amebiasis: modern diagnostic imaging with pathological and clinical correlations. Semin Roentgenol 1997;32:250-75.

24. Kartzeinstein D., Rickerson V., Braude A. New concepts of amebic liver abscess derived from hepatic imaging, serodiagnosis and hepatic enzymes in 67 consecutive cases in San Diego. Medicine 1982;61:237-41.

25. Stoopen M. La ultrasonografia y la tomografia computadorizada em el diagnóstico Del abscesso hepático amibiano. Arch Invest Méd (México) 1980; $11: 317-24$.

26. Shiriniv B., Kakesh J. Amoebic liver abscess CT and MRI. Bombay H J 1997;39:54-62.

27. Assorey A., Aguacyl M.A., Guerra J.M., et al. Amebiasis invasiva. Formas extraintestinales y complicaciones. Diagnóstico parasitológico e serológico. Rev Clin Esp 1985;76:271-8.

28. Tribouley D.R. Utilisation du test ELISA pour le diagnostique serologique de l'amebiase hépatique. Étude comparée avec 4 autres méthodes immunoflorescence, hémaglutination passive et fixation du complement. Bull Soc Path Exot 1982;75:12-5.

29. Haque R., Ali I.K.M., Petri W.A. Jr. Comparison of PCR, isoenzyme analysis and antigen detection of Entamoeba histolytica infection. J Clin Microbiol 1998;36:4449-52.

30. Conter R.L., Pitt H.A., Tompkins R.K., et al. Differentiation of pyogenic from amebic hepatic abscess. Surg Gynecol Obstet 1986; 162;114-7.

31. Barnes P.F., De Cock K.M., Reynolds T.N, et al. A comparison of amebic and pyogenic abscesses of the liver. Medicine 1987;66:472-8.

32. Subramanian R. Amebiasis extraintestinal manifestations. J Assoc Physician Índia 1968; 16:291-4.

33. Elichi E.N., Etawo U.S. hest complications of amebic liver abscess: a report of six cases from Nigeria. East Afr Med J 1994;71:189-92.

34. Greaney G.C., Reynolds T.B., Donavan A,J. Ruptured amebic liver abscess. Arch Surg 1985;120:555-9.

35. Ibarra-Perez $\mathrm{C}$. Thoracic complications of amebic liver abscess: report of 501 cases. Chest 1981;79: 872-7.

36. Landy M.J., Setiawan H., Hersch G., et al. Hepatic and thoracic amebiasis. AJR 1980; $135: 449-54$.

37. Kapur O. P. Clinical syndromes produced by left lobe abscess. Bombay Hosp J 1990;32: 70-8.

38. Mandragom-Sanchez R., Cortez-Espinoza T. Sanchez R., et al. Rupture of an amebic liver abscess into the pericardium: presentation of a case and review of the current management. Hepatogastrenterology 1994; 41: 585-7. 
39. Freeman A.L., Bhoola K.D. Pneumopericardium complicating amoebic liver abscess. S Afri Med J 1976;426:50-2.

40. Adams E.B. Amoebic pericarditis. Medicine 1974;17:1013-6.

41. Gomersall I.N., Currie J., Jeffrey R. Amoebiasis: a rare cause of cardiac tamponade. Brit Heart J 1994;71 336-9.

42. Wallace J.R. Amebic peritonitis following ruptures of an amebic liver abscess. Arch Surg 1978;113:332-5.

43. Eggleston F., Handa H.K., Verghese M. Amebic peritonitis secondary to amebic liver abscess. Surgery 1982; 91:46-51.

44. Ohana J.A. Abdome agudo e amebíase. Col Brás Cir 1987; 1:7-14.

45. Thompson J.E., Forlenza S., Verma R. Amebic liver abscess: a therapeutic approach. Rev Infect Dis 1985; 7:171-9.

46. Araujo R., Bichara C.N., Chaves L.C.. et al. Amebíase. In: Doenças Infecciosas e Parasitárias: Enfoque Amazônico. Pará: Cejup 1997:581-96.

47. Powell S.J., Elsdon R. Metronidazole in amoebic dysentery and amoebic liver abscess. Lancet 1966;2:1329-31.

48. Rol F.J.C. Metronidazole: review of its use and toxicity. J Antimic Chemoth 1977;3:205-9.

49. Huggins D. Drogas antiamebianas. Rev Brás Clin Terap 1982;11:683-700.

50. Magallan A.R. Abscesso amibiano del higado. Tratamiento médico com defirentes esquemas. Rev Hosp Juá México 2000;67:51-4.

51. Salles J.M.C. Avaliação da eficácia do secnidazol na amebíase aguda. Rev Brás Méd Trop 1989;22:33-5.

52. Cabello R.R., et al. Nitazoxanida for the treatment of intestinal protozoan and helminthic infections. Trans Royal Soc Trop Med Hyg 1997;91:701-3.

53. Anderson M.D., Oldfield E.C. Luminal agents for invasive amebiasis: nice or necessary? Am J Gastrenterology 1993; $88: 964-5$.

54. Fernandes P. Emprego do teclosan na amebíase intestinal em dose única. Folha Médica 1978;77:141-5.

55. Salles J.M., Vieira M.T. Avaliação da atividade da etofamida na amebíase intestinal. O Hospital 1970;75:331-6.

56. Reed S.L., Ravdin J.I. Amebiasis. In: Blaser M.J., Smith P.D., Ravdin J.I. Infections of the gastrointestinal tract. 2. ed., New York; Raven Press 1995;133-6.

57. Allan-Jones E., Mindel A., Sargeaunt P.G. Outcome on untreated infection with Entamoeba histolytica in homosexual men with and without HIV antibody. BMJ 1988;297:654-7.

58. Reed S.L., Wessel D.W., Davis C.F. Entamoeba histolytica and AIDS. Am J Med 1990;90:269-71.

59. Cimmerman S. Prevalencia de parasitoses intestinais em pacientes portadores da Síndrome da Imunodeficiência Adquirida (AIDS). Tese (Mestrado) Escola Paulista de Medicina-Universidade Federal de São Paulo. São Paulo, 1998.
60. Saraswat V.A., Agarwal D.K., Baijal S.S., et al. Percutaneous catheter-drainage of amebic liver abscess. Clin Radiol 1992;45:187-9.

61. Ramani A., Ramani R., Kreman M.S. Ultrasound-guided needle aspirate of amebic liver abscess. Postgrad Med J 1993;60:381-3.

62. De La Rey N.J. Indications for aspiration of amebic liver abscess. South Afr Med J 1989;75:376.

63. Rals P.W., Barnes P.F., et al. Medical treatment of hepatic amebic abscess: rare need for percutaneous drainage. Radiology 1987; 165:805-7.

64. Javed I., Syed A.Y. Laparoscopic drainage of liver abscess. Br J Surg 1998;86:330-2.

65. Andre A.R. Surgical considerations in the management of amoebic liver abscess. Bombay Hosp H 1997;39:110-4. 